\title{
Utilizing Demonstrations in Teaching, with an Example Demonstration of Plant Propagation via Cuttings ${ }^{1}$
}

\author{
Isabella Damiani, Andrew Thoron, and J. C. Bunch²
}

\section{Introduction}

In a learning environment, it is important to provide instruction to each type of learner. There are visual, auditory, and kinesthetic learners. Individuals each learn differently, and there are educational tools that can be used to appeal to multiple types of learners (Leopold 2012). Through varying teaching styles and the use of effective tools, teachers aim to reach all of their students. Tools are additions to instruction that aid in providing a more complete lesson. One of these tools is the use of demonstrations. A teaching demonstration is a process that teaches learners how to compete a task using actual materials. The audience level and size can impact the effectiveness of the demonstration (Smith, Wenderoth, \& Tyler 2013).

Bandura's Social Cognitive Theory suggested that individuals learn from one another. This theory is a medium between traditional behavior and cognitive learning theories (Bandura 1999). This theory encompasses individual motivation, attention, and memory. To successfully model a demonstration, an individual must have adequate attention to detail, motivation to complete the task, and proper recollection of the steps. Social Cognitive Theory states that individuals learn via observation, imitation, and modeling (Bandura 1999). Through demonstration, instructors are able to model proper behaviors and techniques for tasks. Students are able to observe the instructor, imitate the action, and model the instructor's technique.
There are beneficial reasons for using demonstrations as a teaching method when teaching agriculture. Demonstrations assist in teaching a skill with multiple steps. It is a way to engage the audience and encourage audience participation. Finally, demonstrations are a way to engage the audience in a more complete way, rather than focusing on simply auditory or visual teaching strategies. Demonstrations, like many other strategies, aid some learners in a more complete understanding of the material.

\section{How to Conduct a Demonstration}

When conducting a demonstration, there are certain considerations the instructor must take into account. First and most importantly, safety precautions, proper tool identification, and technique must be outlined. Safety should always be the top priority when using demonstration as a teaching method. It is important to explain the purpose of the demonstration to the learners and to gauge the learners regarding their level of understanding, as well as ensure all learners have equal opportunity to learn. It is also important to adjust the demonstration so that it is universally accessible, so all learners benefit from instruction. If the audience is large, it may be appropriate to have an assistant complete the demonstration simultaneously in a different area of the room to ensure everyone is able to see, hear, and participate. While conducting the demonstration, it is important to explain each step fully, show steps multiple times (if applicable), have learners

1. This document is AEC643, one of a series of the Agricultural Education and Communication Department, UF/IFAS Extension. Original publication date May 2018. Visit the EDIS website at http://edis.ifas.ufl.edu.

2. Isabella Damiani, graduate assistant; Andrew Thoron, associate professor; and J. C. Bunch, assistant professor; Department of Agricultural Education and Communication; UF/IFAS Extension, Gainesville, FL 32611.

The Institute of Food and Agricultural Sciences (IFAS) is an Equal Opportunity Institution authorized to provide research, educational information and other services only to individuals and institutions that function with non-discrimination with respect to race, creed, color, religion, age, disability, sex, sexual orientation, marital status, national origin, political opinions or affiliations. For more information on obtaining other UF/IFAS Extension publications, contact your county's UF/IFAS Extension office. 
perform the task, and review the demonstration. Once the instructor has demonstrated the task, the learners should perform the task that was demonstrated. After the learners have demonstrated the task, the instructor should review the performance with the learners. It may be beneficial to repeat the entire demonstration. If the demonstration is complex (for example, disassembling a small gas engine), a recording may be used. With a recorded demonstration, the instructor can pause, explain, and repeat the demonstration without wasted materials or extended time conducting the process.

There are many different types of demonstrations that may be used. Visual aids should be used during demonstrations. These may include models, specimens, graphs, charts, videos, etc. Additional items such as whiteboards, chalkboards, and overhead projections of materials (Elmo or smart board) may be used to enhance demonstrations. When using a projector or slides, it is important to ensure all students are able to accurately see the screen, especially if the instructor is unable to describe each step in enough detail through oral instruction.

When using demonstrations as a teaching method, the following five-step process is important to remember when designing the lesson. Table 1 describes the five-step process.

Table 1. Five steps to teaching with demonstrations.

\begin{tabular}{|l|l|}
\hline Prepare & $\begin{array}{l}\text { The instructor should gather materials for the } \\
\text { demonstration and prepare the room or area for the } \\
\text { demonstration to take place. Readings or videos that the } \\
\text { students should view at home should be provided well } \\
\text { in advance of the demonstration. }\end{array}$ \\
\hline Tell & $\begin{array}{l}\text { The instructor should tell the learners the importance of } \\
\text { the demonstration and explain each step of the process } \\
\text { to complete the task. }\end{array}$ \\
\hline Show & $\begin{array}{l}\text { The instructor should demonstrate to the learners each } \\
\text { step of the process to successfully and safely complete } \\
\text { the task. }\end{array}$ \\
\hline Do & $\begin{array}{l}\text { The learners are given the opportunity to complete the } \\
\text { task, or steps in the task, on their own. }\end{array}$ \\
\hline Review & $\begin{array}{l}\text { The instructor provides the opportunity for the learners } \\
\text { to review the steps involved in the task. }\end{array}$ \\
\hline
\end{tabular}

\section{Considerations}

It is important to be aware of a few key considerations. Safety is the most important consideration when performing any type of demonstration. Safety precautions should always be outlined to the audience before they attempt the process and reminded throughout the process. It is vital that the learners understand any risks or precautions they must make. The second most vital consideration is the amount of time needed to demonstrate and allow for practice. It is important to fully explain the demonstration and not try to rush the process. The learners must have an appropriate amount of time to complete the task that is demonstrated. To ensure safety and understanding, they must not rush. Additionally, audience members will be seeing a mirror image of the task (Roberts 2012). This could create confusion in some demonstrations. Not all audience members will grasp the demonstration, and different individuals will struggle with different steps. Adapting your material to be universally accessible will ensure that all of your students are reached. It is important to be aware of these considerations when using demonstrating as an effective teaching tool.

\section{Conclusions}

Demonstrations are a valuable teaching tool that aids in teaching a specific task or project. Demonstrations can appeal to different learning styles and aid in a more complete understanding for individuals. However, for a demonstration to be effective, certain considerations must be made. A demonstration must be fully explained in a way that all audience members have equal opportunity to understand. Potential physical, financial, and mental limitations may be present for both the presenter and the audience. However, if a demonstration is done effectively, it can be a powerful teaching method. The following example can easily be modified as you develop appropriate demonstrations for your classroom.

\section{Plant Propagation via Cuttings EQUIPMENT REQUIRED}

1.Sharp knife, scissors, or nippers

2. Plant pot or something to use as a plant container

3. Growing media

4. Pencil

5. Clear or semi-clear plastic bag (e.g., vegetable bag from store or freezer bag)

6. Rubber band

7. Stem or leaf cutting

\section{HOW TO TAKE PLANT CUTTINGS}

1. Mix up the growing media.

2. Saturate the growing media with water. 
3. Make hole in media for cutting.

4. Begin with a cutting.

5. Remove the lower leaves from the cutting.

6. Use rooting hormone on cut portion of the stem/leaf.

7. Cover the rooting portion of the cutting with media.

8. Cover the pot with a bag or put under shade and with misting system.

9. Place the cuttings in a suitable location and wait.

See below for more detailed information and images.

\section{STEP 1. MIX UP THE GROWING MEDIA}

Mix equal amounts of sand and potting compost together. Fill the pot with this mixture to a level just below the rim to facilitate watering.

Allow students to feel different mediums and make observations on texture, smell, and visual differences among the components. This can be an opportunity to talk about particle size, water holding capacity, and other important factors for proper medium selection.

Safety: Some media has irritants in it that may irritate the skin or eyes and potentially be harmful if inhaled. It is important to explain the safety precautions used with the media you are using, especially if the medium contains sphagnum or pearlite. Sphagnum is irritating to the skin, and pearlite dust can be damaging to the lungs if inhaled.

\section{STEP 2. SATURATE THE GROWING MEDIA WITH WATER}

\section{STEP 3. MAKE A HOLE IN MEDIA FOR PLACING THE CUTTING}

Use a pencil to create a hole in the growing media to place the plant stem. This prevents the rooting hormone from being displaced during planting.

\section{STEP 4. BEGIN WITH A CUTTING}

The length varies and depends on the plant. When taking cuttings from a shrub, generally cut a piece from 6 to 8 inches in length. Make a clean cut with nippers about $1 / 4$ inch below a leaf joint. You may also use a sharp knife, scissors, or snips. Roots sprout from the nodes where the leaves meet the stem. It is advantageous to get as many of these nodes at the lower end of the cutting to promote rooting success.

Safety: Ensure the student is being supervised when using any sharp and potentially dangerous tools. It is important for the instructor to demonstrate how to properly and safely use the tools.

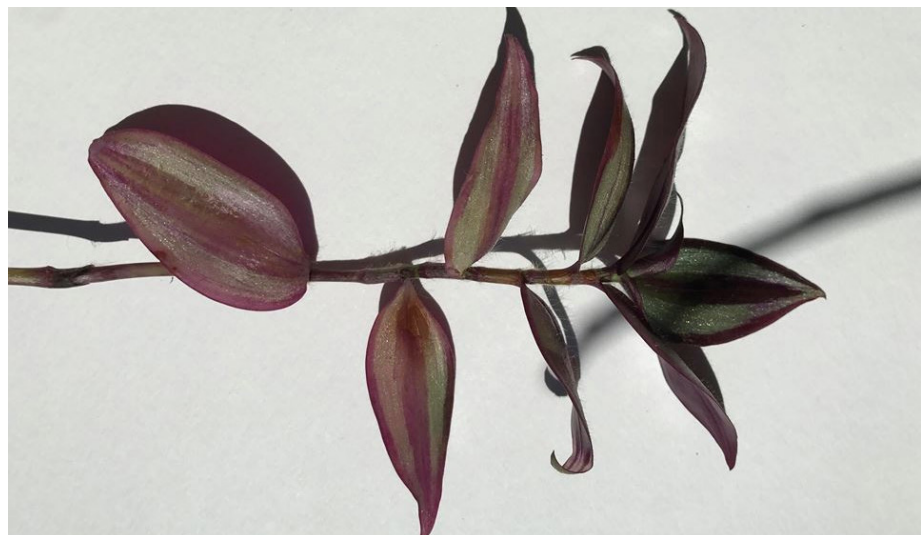

\section{STEP 5. REMOVE THE LOWER LEAVES FROM THE CUTTING}

Remove the leaves from the lower $1 / 2$ to $2 / 3$ of the cutting by gently pulling them off.

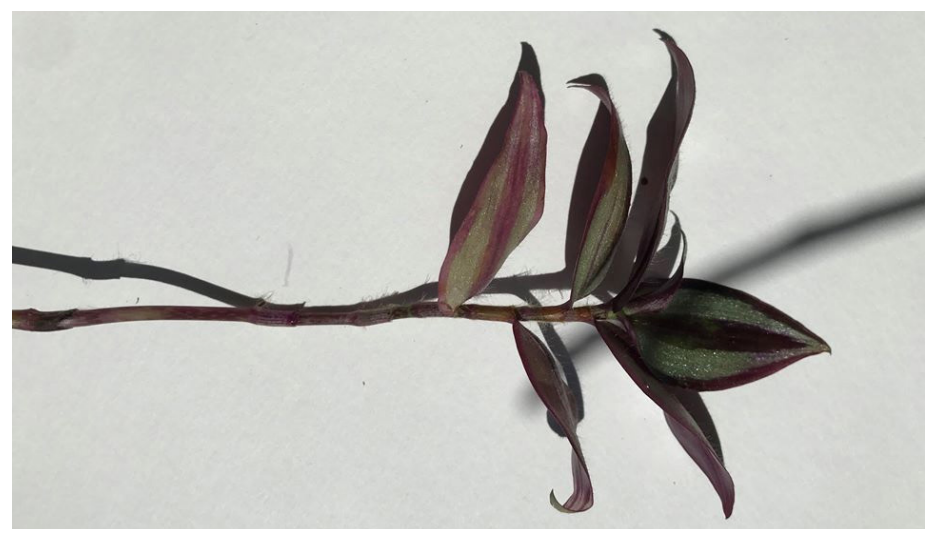

\section{STEP 6. USE ROOTING HORMONE ON CUT PORTION OF THE STEM/LEAF}

Certain plants require rooting hormone to root successfully. You can use hormone rooting powder/liquid as an aid. You dip the end of the cutting in water, tap off the excess water, insert the end into rooting powder, tap off the excess powder, and then push the cutting down into the medium.

Safety: Rooting hormone can be an irritant on skin, eyes, or when inhaled. It is important that students wear proper PPE (gloves, masks, glasses/goggles) when handling rooting hormones. 


\section{STEP 7. COVER THE CUTTING WITH MEDIUM, GENTLY}

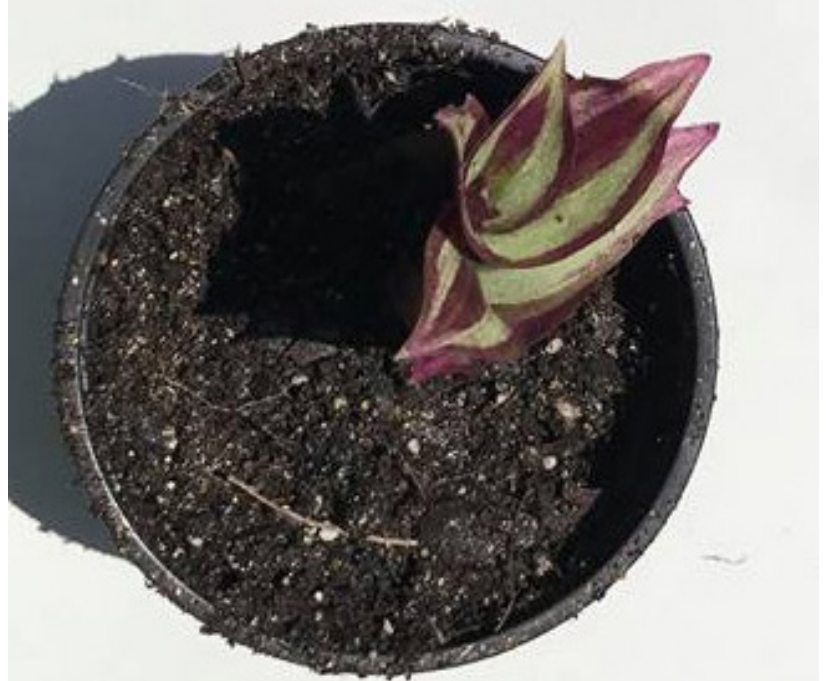

\section{STEP 8. COVER THE POT WITH A NAG OR PUT UNDER SHADE WITH A MISTING SYSTEM}

The process of transpiration transports water and nutrients throughout the plant. Heat and light acting on leaves causes water to evaporate via pores on the surface of the leaves (stomata). Water rises via the xylem within the plant to replenish the evaporated water. This is known as capillary action. When a cutting is taken from the original plant, it loses its roots, and thus its ability to take up water. This inability can lead to plant damage and even death. This damage and death can be elevated by high humidity levels during the root establishment process of plant propagation.

Cover the pot with a clear or semi-clear plastic bag, held in place with a rubber band. Make a hole in the top of the bag. This allows some ventilation, prevents the air from becoming overly humid, and discourages mold growth on the leaves.

Variations of covering, hole puncture, and placement can be used to allow students to observe differences among the methods.

You can put the plant in a shade house with a misting station if one is available at your school. The plants should be misted every hour for five minutes.

\section{STEP 9. PLACE THE CUTTINGS IN A SUITABLE LOCATION, AND WAIT}

Do not place the cuttings in direct sunlight. Depending on the plant, temperature, and humidity, cuttings may root in as little as two to three weeks. After two weeks, check the bottom of the pot for rooting. Once rooting has been established, transplant the plants to larger pots and gradually increase plant size as root density increases.

If you are working with a student who is visually impaired, you may rinse the roots and allow them to feel the roots of a freshly propagated cutting versus their two-week-old propagation. It is important to have universally accessible learning opportunities.
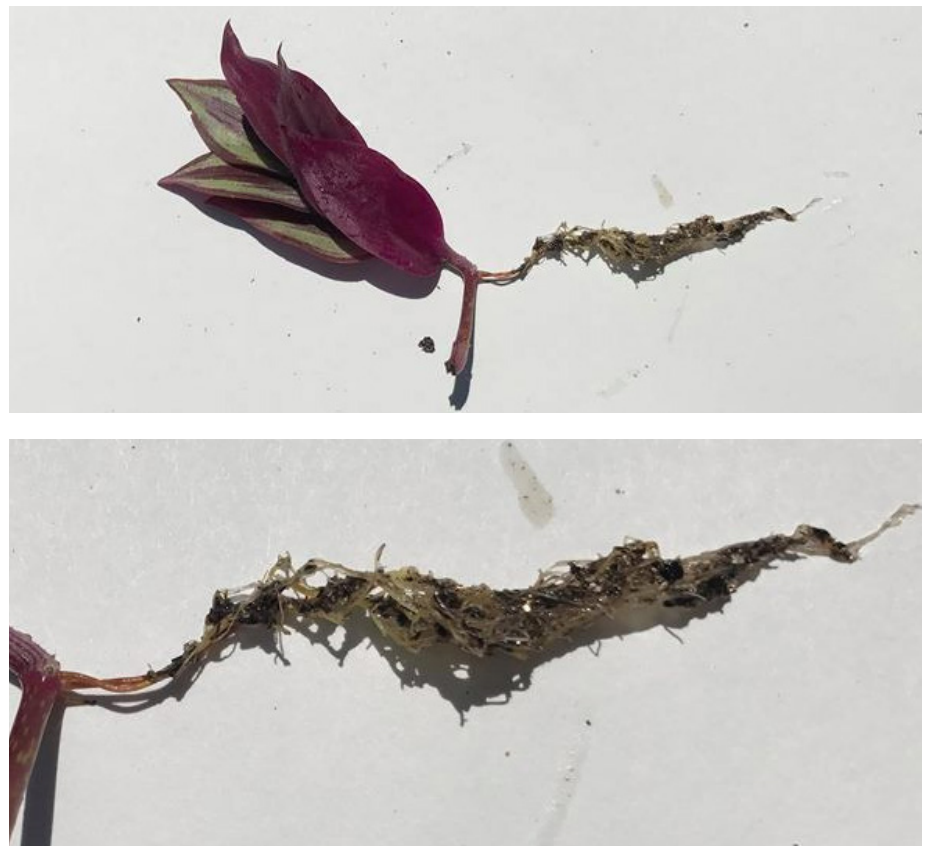

\section{References}

Bandura, A. (1999). Social cognitive theory: an agentic perspective. Asian Journal of Social Psychology 2: 21-41.

Leopold, L. (2012). Prewriting Tasks for Auditory, Visual, and Kinesthetic Learners. TESL Canada Journal 29(2): 96-102.

Roberts, T. G. [Cornell SIPS]. (2012, October 25). [mp4] https://www.youtube.com/watch?v=6n5FTq7mEd0

Smith, M. K., Wenderoth, M. P., and Tyler, M. (2013). The teaching demonstration: What faculty expect and how to prepare for this aspect of the job interview. CBE-Life Sciences Education 12(1): 12-18. doi:10.1187/cbe.12-09-0161 